\title{
CRISTÓBAL DE ROJAS: NUEVOS DATOS SOBRE SU BIOGRAFÍA Y PRIMERAS OBRAS
}

\author{
Pedro Luengo ${ }^{1}$ \\ Universidad de Sevilla
}

\begin{abstract}
La biografía del ingeniero militar Cristóbal de Rojas era poco conocida hasta el momento. Este artículo pretende ofrecer nuevos datos sobre la misma, tanto en sus orígenes, como en su posible formación y aparición en Sevilla. Posteriormente se aborda la realización de lo que sería su primera obra documentada: la portada del hastial de la parroquia de Cañete de las Torres (Córdoba). Además, se plantea delimitar su participación en la obra de El Escorial a un contacto con los círculos matemáticos de Juan de Herrera, como parte de su capacitación como ingeniero con Tiburcio Spanocchi. Finalmente se ofrecen algunas novedades sobre sus distintos matrimonios.
\end{abstract}

Palabras clave: Ingeniería militar; Cañete de las Torres; El Escorial; Hernán Ruíz III; arquitectura renacentista.

\section{CRISTÓBAL DE ROJAS: NEW BIOGRAPHICAL INFORMATION AND FIRST WORKS}

The biography of the military engineer Cristóbal de Rojas was little known until now. This article aims to offer new data concerning his origins, possible formation and first appearance in Seville. Then his first documented work, the front doorway of the parish church of Cañete de las Torres (Cordoba), is analyzed. Thanks to this, it is possible to delimit his participation in the work of El Escorial to a contact with the mathematical circles of Juan de Herrera, as part of his training as an engineer with Tiburcio Spanocchi. Finally, this paper presents new information concerning his several marriages.

Key words: Military engineering; Cañete de las Torres; El Escorial; Hernán Ruíz III; Renaissance architecture.

Como citar este artículo / Citation: Luengo, Pedro (2018): "Cristóbal de Rojas: nuevos datos sobre su biografía y primeras obras”. En: Archivo Español de Arte, vol. 91, núm. 362, Madrid, pp. 113-126. https://doi.org/10.3989/aearte. 2018.08.

La figura de Cristóbal de Rojas puede considerarse como una de las más destacadas de la ingeniería militar y la arquitectura española en el paso del siglo XVI al XVII. A pesar de haberse definido ya un catálogo numeroso de obras e intervenciones de este ingeniero, muchos de sus aspectos biográficos seguían siendo aún desconocidos o dados por buenos desde la primera biografía de este autor, realizada por Mariátegui en el siglo XIX². Más recientemente han sido notables los intentos por condensar la carrera del ingeniero, aunque la visión decimonónica seguía manteniéndose por falta de nueva documentación que la sustituyera ${ }^{3}$. Este artículo tiene como objetivo esclarecer diferentes aspectos biográficos del ingeniero, lo que permitirá en primer lugar hacer una revisión de su posible etapa formativa, incluyendo además lo que sería hasta el

\footnotetext{
1 pedroluengo@us.es / ORCID ID: http://orcid.org/0000-0003-0462-4921.

2 Mariátegui, 1880.

${ }^{3}$ La última aproximación destacable la ofrece Cámara, 2014: 135-161. Otros autores han abordado aspectos puntuales de su carrera. Ríos, 2001: 13-25. Takayanagi, 2009: 273-281.
} 
momento su primera obra en cantería. Posteriormente, prevé analizar sus primeros años como maestro, delimitando cronológicamente su presencia en la corte. Por último, se ofrece una revisión de sus últimos años de vida en Cádiz, a partir de sus diferentes matrimonios. Todo esto permite plantear una visión más detallada de la vida y posible formación de este autor, lo que ayuda a entender mejor sus obras.

Para alcanzar estos objetivos ha sido fundamental cruzar información documental de diferentes archivos andaluces, hasta ahora obviados, con otros más utilizados. Principalmente se trata del Archivo General de Indias, del Archivo General del Obispado de Córdoba y del Archivo de la Parroquia de Santa Cruz de Cádiz. A estas fuentes inéditas habría que unir aquellas ya conocidas, que en algún caso toman un significado mayor. Uno de los trabajos más complejos ha sido el de revisar la cita de los hechos conocidos, que en un número notable estaban confundidos en décadas entre diferentes estudios. Sólo después de cotejar esta información con los originales, ha sido posible plantear esta recomposición de su biografía. Además de esta revisión biográfica, que se pone en relación con otras figuras similares del período, se ofrece un análisis formal de la que puede ser su primera obra desde la perspectiva formativa.

\section{El maestro cantero Cristóbal de Rojas: fruto de la escuela andaluza}

La primera biografía del personaje ubicaba su nacimiento en Toledo en 1555. La elección de la ciudad se hacía en base a una creencia popular, sin ningún apoyo documental, como el mismo Mariátegui afirma ${ }^{4}$. De hecho, profundos trabajos sobre la arquitectura toledana de estas fechas, no han aportado ninguna información sobre este personaje ${ }^{5}$. Con posterioridad, Falcón propuso Baeza como su lugar de nacimiento, aunque manteniendo la fecha ${ }^{6}$. Más recientemente, Luengo lo puso en relación con la figura de un maestro cantero homónimo con licencia de viajes a Filipinas, pero sin confirmar si pudiera tratarse del mismo ${ }^{7}$. En caso de aceptar esta última opción, el personaje habría nacido en Cañete de las Torres (Córdoba), antes de la fecha señalada, probablemente en 1552. De todas las dataciones mencionadas es la única que, por el momento, cuenta con respaldo documental conocido.

La fecha de nacimiento de 1555 está basada en el retrato incluido en su libro Teoría y práctica de la fortificación (Madrid, 1598). El grabado está firmado por el pintor Pedro Román en 1597, y en el mismo se hace referencia a que el retratado contaba con 42 años. Tal datación ofrece problemas con otros documentos del propio Rojas. Así, como indica Cámara, el ingeniero tendría solo veinticuatro años cuando Tiburcio Spanocchi lo llevaría a la corte como un destacado maestro ${ }^{8}$. Más difícil aún es el hecho de que llevara cuarenta años de profesión en 1602, lo que implicaría que empezó a trabajar en cantería con sólo siete años si hubiera nacido

4 Mariátegui, 1880

5 Marías, 1985.

${ }^{6}$ El documento utilizado está citado como Archivo Municipal de Sevilla. Colección Conde del Águila. IX. 27. Falcón, 1977: 42. Desgraciadamente, la consulta del documento citado no confirma este planteamiento, lo que hace pensar que el investigador debió tomar la cita de otra fuente que hoy no se conoce, ni en ubicación ni en términos. En el mismo fondo sí se encuentra un documento de Rojas, donde no se hace mención a sus orígenes, transcrito aquí en su plenitud: "Memoria del arquitecto Cristóbal de Rojas, 1589/ Cristóbal de Rojas arquitecto vecino de esta ciudad/ digo que para curiosidad del arte de arquitectura yo / he dejado sacar una dirección y plano de esta ciudad/ con todo su circuito para después poder[lo] pintar / y sacar al natural como lo andan en otras ciudades / en estampas y porque de esto se pudieran ofre/cer muchas ocasiones para el servicio del rey/ nuestro señor y de esta ciudad teniéndola sacada en limpio./ Pido y suplico a vuestra señoría me conceda su / licencia para lo poder hacer y pido licencia. / Cristóbal de Rojas" (rúbrica). Archivo Histórico Municipal de Sevilla (AHPS). Índice Sección III. Siglo XVI. Tomo XII. NOP, N. ${ }^{\text {a }} 57$, f. 210 r.

7 Luengo, 2018.

${ }^{8}$ Cámara, 2014. Otra reciente biografía de este ingeniero se debe a Sobradiel, 2015. 
en $1555^{9}$. Todo ello, unido a la escasa solidez de la referencia en el tratado, llevaría a pensar que la fecha de 1555 pudiera no ser muy precisa. Si se relaciona la documentación del maestro cantero con el ingeniero, aquel habría nacido en 1552 aproximadamente, en Cañete de las Torres ${ }^{10}$. Desgraciadamente, ningún documento de este cordobés está firmado, conservándose sólo informes realizados por terceros. Afirmaría tener veintiséis años a finales de 1578 , poco antes de su viaje fallido a las Indias. Retomando lo dicho, tendría veintisiete años cuando pasó a Madrid y en torno a diez años cuando se inició en la disciplina. Estas fechas, aunque tempranas, son más propias del momento histórico que las hasta ahora aceptadas.

Este personaje estaría ya casado en 1578 con María Rodríguez, natural de Montoro, y tendría un único hijo llamado Lorenzo, de ocho años de edad. Ninguno de ellos volvería a ser mencionado en relación con el ingeniero en toda su carrera. Los padres del cantero serían Bartolomé Rojas y María Nogales ${ }^{11}$. Desgraciadamente, a pesar de este nuevo dato, no se ha podido comprobar la posible relación entre el cantero Gonzalo de Rojas y el citado Bartolomé12. El primero es criado de Alonso Rodríguez desde 1506, siendo aparejador de las obras de la catedral entre 1507 y 1524, cuando falleció, pero se desconoce su descendencia. Sobre sus antecedentes familiares hay que retomar la propuesta de Mariátegui sobre el blasón aparecido en el citado retrato de 1597. En la esquina superior izquierda se ubican las armas de la familia Rojas: en campo de oro cinco estrellas de azur de ocho rayos puestas en sotuer. Como timbre aparece un yelmo siniestrado, propio de los caballeros bastardos ${ }^{13}$. Posiblemente esta colocación apunte a que no pertenecía a la saga cordobesa que estaba intentando probar su nobleza en la Chancillería de Granada desde mediados del siglo XVI ${ }^{14}$. Un último elemento de la biografía decimonónica que debe revisarse es su vinculación como colegial con la Universidad de Alcalá. Efectivamente aparece un personaje con este nombre entre 1566 y 1577, natural de Madrid, pero resulta difícil pensar que se tratara del futuro ingeniero militar, que habría entrado a estudiar con sólo once años ${ }^{15}$.

Por último, cabe confirmar que el personaje con licencia de pasaje a Indias no llegara finalmente a su destino ${ }^{16}$. Cristóbal de Rojas aparece como parte del séquito del recién nombrado gobernador de Filipinas, Gonzalo Ronquillo. Se trata de un grupo de más de doscientas personas, entre las que se encuentran dos carpinteros y sólo este maestro cantero, viajando en todos los casos con sus familias. Es conocido que Ronquillo fue buscando diferentes profesionales para que le acompañaran a Manila, como siguió haciendo tras su parada en Panamá en 1579. Lo que parece seguro es que Rojas no llegó a Filipinas y al parecer tampoco al continente americano. La escasez de profesionales de la construcción en el archipiélago, y la documentación conservada no apunta en ningún caso el nombre de Cristóbal de Rojas ${ }^{17}$. Tampoco se ha podido localizar en América, donde ha llegado a confundirse repetidamente con Cristóbal de Roda Antonelli, pero

\footnotetext{
9 "la experiencia que tengo de cuarenta años a esta parte en hacer fábricas como por haber salido de España a ver las cosas de la guerra". Archivo General de Simancas (AGS), Guerra y Marina, Leg. 623, f. 146. Sobradiel, $2015: 136$.

10 El archivo sacramental de la parroquia de Cañete de las Torres se ha perdido completamente para estas fechas por lo que es imposible localizar la partida de bautismo correspondiente.

11 Nada puede confirmarse sobre la identidad de los progenitores. Existe un guadamecilero con este nombre en Córdoba, que viviría entre 1531 y 1561, lo que podría encajar con el padre del ingeniero. En ese caso, sería hijo a su vez de Bartolomé Sánchez. Torre, 1952: 16.

12 Rodríguez, 1996: 69.

13 Mariátegui, 1880: 12.

14 Barea, 2015: 171-173.

15 Archivo Histórico Nacional (AHN), Universidades, L. 477, f. 43v y L. 478, ff. 15, 117, 249v., 341, 470.

16 "Maestro de Cantería. Cristóbal de Rojas, es natural de Cañete / en el marquesado de Priego, hijo de / Bartolomé de Rojas y de Margarita/ Nog[a]les de edad de veinte y seis años de / buen cuerpo ojizarco y poca barba, / y lleva consigo a María Rodríguez / su mujer natural de Montoro, hija / de Miguel Sánchez y de Isabel / González, alta de cuerpo y delgada / de edad de veinte y tres años y Lo/renzo su hijo de edad de ocho años / [...] lleva las armas de que su majestad manda". Archivo General de Indias (AGI), Contratación, 5227, N.1, R. 10, 27r. Según la datación del archivo este documento completo es de noviembre de 1578, por lo que la información debe ser ligeramente anterior.

17 Díaz-Trechuelo, 1959. Ver también Luengo, 2018.
} 
cuyo nacimiento en 1560 y sus claros vínculos con la familia de ingenieros de origen italiano no dejan lugar a dudas de que son dos personajes claramente diferenciables ${ }^{18}$.

\section{Cristóbal de Rojas y su primera estancia en Sevilla}

Localizado inicialmente Rojas en la provincia de Córdoba, es posible que su formación como cantero se diera en los círculos de Hernán Ruíz III (1534-1606) e incluso de Alonso de Vandelvira (1544-1626), como se mostrará al abordar su primera obra documentada ${ }^{19}$. Pero a pesar de esto, su primera intervención es anterior. Un dato conocido, pero no valorado suficientemente es la participación de Cristóbal de Rojas en las discusiones sobre la construcción de la Sala Capitular de la catedral sevillana en $1572^{20}$. Tras informar Pedro Díaz de Palacios, se continuó preguntando a otros "maestros mayores (...) de Toledo y Jaén". Así se solicitó el parecer de Alonso de Covarrubias y Andrés de Vandelvira, y por fallecimiento del primero en 1570, se llamó al de Córdoba, Hernán Ruíz III. Probablemente ante la negativa de éste de contribuir a la discusión, se optó por Cristóbal de Rojas, quien no debía ser maestro mayor de ninguna sede aún, pero debía estar bien relacionado con estos personajes consolidados. Así, mantener la fecha tradicional de su nacimiento de 1555, implica que realizaría el dictamen con sólo diecisiete años, mientras que optar por 1552 lo ubicaría en Sevilla con veinte aproximadamente. Esto acercaría la precocidad del ingeniero a la de otros personajes cercanos cronológicamente como Hernán Ruíz II, quien inició su carrera de forma temprana, con veintiún años, pero siempre bajo la guía de su progenitor $^{21}$. De la documentación es imposible saber si se trasladó a Sevilla o trabajaba ya en ella. Lo que parece claro es que antes de 1578 estaría en Córdoba para afrontar las obras de la fachada de la parroquia de su pueblo natal.

En estos años de formación, quizás entre Córdoba y Sevilla, el ingeniero tomó buena nota de las particularidades de los materiales disponibles. Así, un elemento interesante que confirmaría el origen formativo del ingeniero militar con la zona central de Andalucía la ofrece su propio tratado de fortificación. Al hablar de los diferentes tipos de piedra utiliza el término "panalejo":

Hay otra que llaman de panalejo, esta es buena para los cerramientos de bóvedas, o capillas, por ser liviana, aunque la más a propósito para los edificios es la piedra berroqueña ${ }^{22}$.

Esta referencia, se trata de una nomenclatura muy excepcional que hace referencia a canteras situadas entre las actuales provincias de Córdoba, Málaga y Granada. Este nombre se encuentra de forma continua desde el siglo XIX $^{23}$ hasta estudios de fecha reciente como un localismo recurrente $^{24}$. No ha podido localizarse en cambio, en otras provincias españolas. La actividad de Rojas entre la finalización del Monasterio de El Escorial en 1584 y la edición del citado tratado

18 Emmer, 1999: 316. Sobre la familia Antonelli existe un estudio reciente de Arrighetti/Carusone/Ceccaroni/Zavalloni, 2009: 565-583.

${ }^{19}$ La estrecha relación entre Alonso de Vandelvira y Cristóbal de Rojas ya fue apuntada por estudios como Herrera, 2014: 95-119.

${ }^{20}$ Recio, 1999: 130. Sobre este espacio ver también Morales, 1984.

${ }^{21}$ Morales, 1996: 24.

22 Rojas, 1598: 90v.

23 "En la entrada de este último pueblo (Churriana), yendo de Málaga, y después en Torre Molinos donde desenvuelta la formación terciaria superior en grande escala, constituye y da lugar a la explotación de los cantillos cavernosos llamados de panalejo que se emplean para edificar". Marzo, 1851: 375. Otro ejemplo similar es: "Panalejo, llaman a la arenisca caliza que traen de Escúzar para los edificios; parece que sólo llaman Panalejo a la toba que se trae excelente de Alfacar, muy cerca de la Piedra de Aguas". Rojas Clemente, 2001.

${ }^{24}$ Varios casos recientes citan expresamente que "se trata de un edificio semisubterráneo (...) de la llamada piedra de panalejo, procedente de las canteras antiguas existentes junto a las ruinas de la ciudad ibero-romana de Ategua". Espejo, 2002: 110-111. Otro estudio indica que la "'piedra de panalejo', es una arenisca muy porosa y de fácil labrado procedente de las antiguas canteras existentes en la Sierra de Montilla, que también se ha empleado con profusión en 
es bien conocida, sin que se haya documentado trabajo alguno en Córdoba. Esto apoya la hipótesis de que Rojas procedía de esta zona andaluza, ya que debió conocer este material antes de su llegada a Madrid en 1579.

\section{Cañete de las Torres: la primera obra conservada}

Vincular al ingeniero militar con el homónimo maestro cantero cordobés, implica que su primera obra conocida sería la portada del hastial de la iglesia parroquial de Cañete de las Torres. Este personaje sería el encargado de diseñarla, en lo que es hasta el momento la primera obra del ingeniero (fig. 1). Había sido tasada en 1577 por el maestro mayor del obispado de Córdoba, Hernán Ruiz III (Doc. 1) ${ }^{25}$. Según se indica en la propia fachada "acabose esta obra a 4 de abril año de 1578 ". Fue levantada en piedra de Santiago y pagada por la fábrica con algunas contribuciones de Inés de Nápoles, vecina de Jaén.

La estructura que cobija el vano se organiza en dos cuerpos. El inferior se articula con dos semicolumnas dórico-toscanas y las correspondientes retropilastras sobre pedestales (fig. 2). Estos ofrecen en su frente un registro rectangular con un óvalo al centro, enlazado en sus puntos medios a las molduras de enmarque. Tal motivo se relaciona con modelos de Hernán Ruíz II, como demuestra la decoración del intradós de los arcos de la iglesia del Hospital de las Cinco Llagas, y es cercano a la solución adoptada en el trascoro de la Catedral de Córdoba en la que participaron Hernán Ruíz III y Juan de Ochoa. La solución aparece igualmente en la plancha "Dorica" de Vredeman de Vries (1577) ${ }^{26}$. En los laterales del pedestal aparece una decoración con rombos que también recuerdan las obras de Hernán Ruíz $\mathrm{II}^{27}$. El fuste acanalado también plantea sugerentes particularidades. Las estrías están rellenas en la parte inferior, pero alternativamente ocupan un tercio o más, marcando hasta tres niveles diferentes. Los fustes acanalados rellenos son habituales en la obra de Hernán Ruíz II, pero sin mostrar esta particularidad, que tampoco aparece en otros tratados de la época. El único caso donde ha podido encontrarse una referencia similar lo ofrece la lámina "Corinthia" del citado Vredeman de Vries, pero la alternancia de alturas es mucho más libre y limitada que en esta fachada.

Sobre estas semicolumnas descansa el entablamento con un friso de triglifos con gotas y metopas decoradas por pateras, cuya alternancia interrumpen dos ménsulas. La decoración de las metopas no es muy habitual en la arquitectura del momento, pero es la que aparece en el folio 49 del Libro de arquitectura de Hernán Ruiz II, y en algunas de sus obras como la portada de la iglesia de Nuestra Señora de la Esperanza en Corterrangel (Huelva) y, tanto en la primera edición de Vignola (1562), como en la posterior traducción al castellano de 1593 (lámina X) ${ }^{28}$. El hecho de incluir ménsulas en el friso no responde a los modelos clásicos, aunque aparece en la posterior edición de Vignola de 1593 (Lámina XXXII), y tampoco es una solución habitual en Andalucía en estas fechas. De hecho, podría considerarse una relación con la producción de Alonso de Vandelvira, quien en algunas obras las incluye ${ }^{29}$. En estos casos, son ménsulas con triglifos, muy

numerosas casas señoriales del casco urbano montillano"; "piedra de panalejo: en Montilla, piedra arenisca muy porosa y de fácil labrado procedente de las antiguas canteras existentes en la Sierra del término". Florido, 1996: 172 y 429.

25 “[piedra vendida]. Cargan se le más veinte reales/ por que vendió la piedra que / se sacó de la portada que se ha / hecho de nuevo en la dicha/ iglesia/ Esta fábrica por mandado / del señor provisor /tomó a censo treinta y cinco// mil maravedies de principal para hacer/la dicha portada los cuales se/ tomaron a censo a catorce mil maravedis/ el millar maravedies de Francisco de Torres/ va en catorce de setiembre / del año pasado de setenta / y hecho de que ha de pagar la fá/brica en cada un año dos mil / y quinientos maravedies de renta”. Archivo General Obispado de Córdoba (AGOC). Visita General n. ${ }^{\circ}$ 6.226/01. Leg. 14. Pieza 10. F. 6v-7r.

26 Vredeman, 1577 a y $1577 \mathrm{~b}$.

27 Aparecen por ejemplo en los pedestales de uno de sus proyectos de retablos incluidos en su tratado de arquitectura. Hernán Ruiz II. Libro de arquitectura. F. 122

28 Vignola, 1593.

${ }^{29}$ Cruz, 2001. 


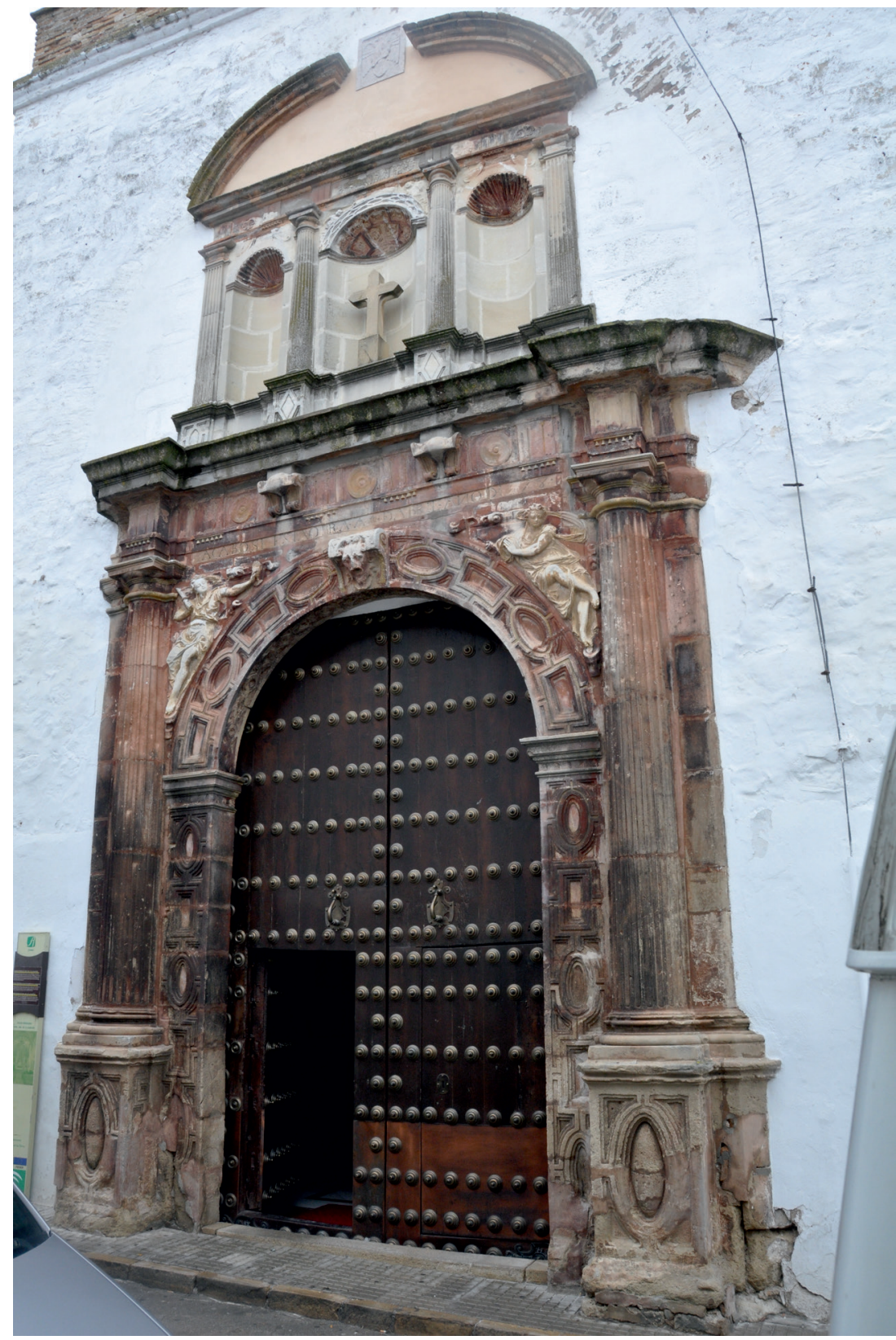

Fig. 1. Córdoba. Cañete de las Torres. Parroquia de la Asunción. Portada oeste. Fotografía del autor.

diferentes a las de Cañete. De hecho, las de esta portada son excepcionales, y parecen apuntar a soluciones posteriores. De nuevo, una posible solución es que Rojas se basara en las ménsulas imaginativas ubicadas por Vredeman de Vries junto a metopas en su tratado de $1577^{30}$.

El arco de acceso presenta en su rosca y en los pilares de apoyo una decoración geométrica alternando trapecios y óvalos. Este tipo de solución no es habitual en las portadas de la época, con la notable excepción de la iglesia del Hospital de las Cinco Llagas (Sevilla) de Hernán

30 Vredeman, 1565: Lámina 8. 
Ruiz II, cuyo modelo además aparece en su Libro de Arquitectura (fol. 4). Los modelos decorativos, por otro lado, son muy similares a los recogidos por Alonso de Vandelvira en su manuscrito, realizado entre 1574 y $1591^{31}$. En la clave aparece un mascarón que también puede estar basado en las ménsulas figurativas publicadas por Vredeman en 1577 (fig. 3) 32 . Aunque las obras de este momento suelen presentar ménsulas en las claves, las representaciones figurativas no son comunes hasta fechas posteriores. Las características escultóricas, en cambio, sí responden al siglo XVI. Cabe indicar, que también Ginés Martínez de Aranda plantea ménsulas con decoración, en este caso vegetal, que podrían asimilarse con las de $\mathrm{Ca}$ ñete en casos como la fuente de Santa María de Baeza.

En las enjutas se ubican dos relieves alegóricos de lo que seguramente sean virtudes teologales: Fe a la izquierda, con el cáliz y la espada como atributos y una segunda desconocida por no conservarse ningún atributo, que podría ser una representación de la Caridad (figs. 4 y 5). Así aparece, al menos, tanto en el arco del presbiterio de la iglesia de Santa Águeda de Sorihuela de Guadalimar, fechada en 1571 como posible obra de Sebastián de Solís, como en la portada de la iglesia de San Pedro de Úbeda, obra de Alonso de Barba, discípulo de Alonso de Vandelvira entre 1605

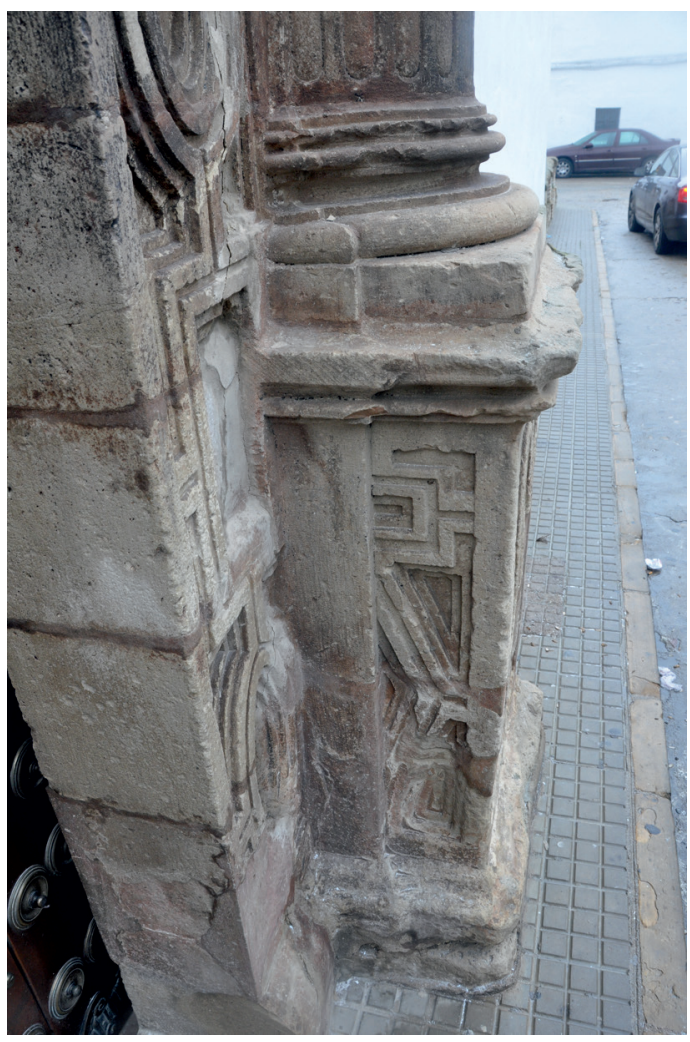

Fig. 2. Córdoba. Cañete de las Torres. Parroquia de la Asunción. Portada oeste. Detalle del lateral del pedestal derecho del primer cuerpo. Fotografía del autor. y 1615. Formalmente pueden relacionarse con los profetas y los gnudi de Miguel Ángel para la Capilla Sixtina, pero sin corresponder con ninguno en concreto.

El segundo cuerpo no tiene la monumentalidad del inferior. Este tipo de solución con triple vano rematado por un arco de medio punto rebajado tampoco es muy común. Un ejemplo simi-
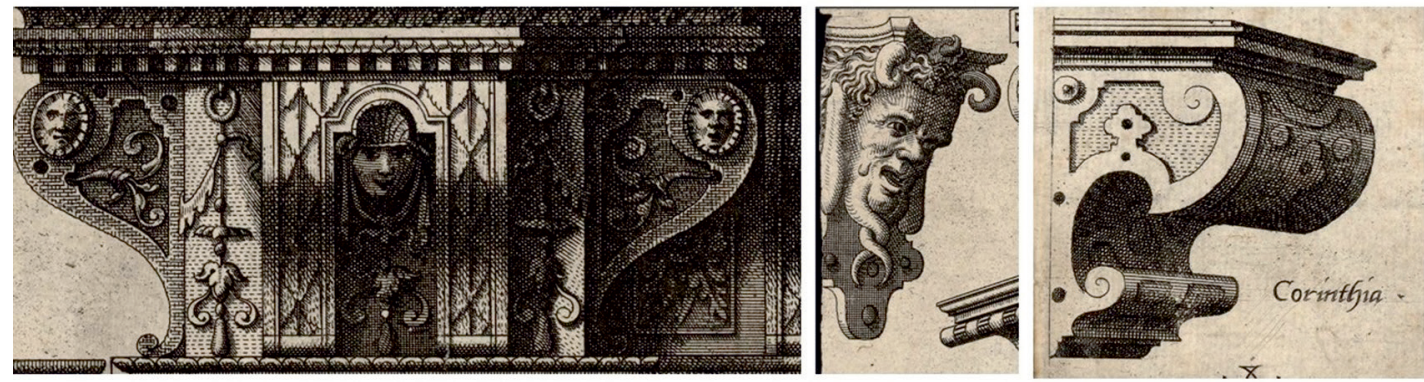

Fig. 3. Jean Vredeman de Vries. Das ander Buech. 1565. Detalles de láminas 20 (Composita) [izquierda y centro] y 8 (Corinthia) [derecha].

31 Vandelvira/Barbé-Coquelin, 1977: Intento 92.

32 Vredeman, 1565. Más concretamente, parece una mezcla de soluciones aparecidas en las láminas 4, 9 y 14. 

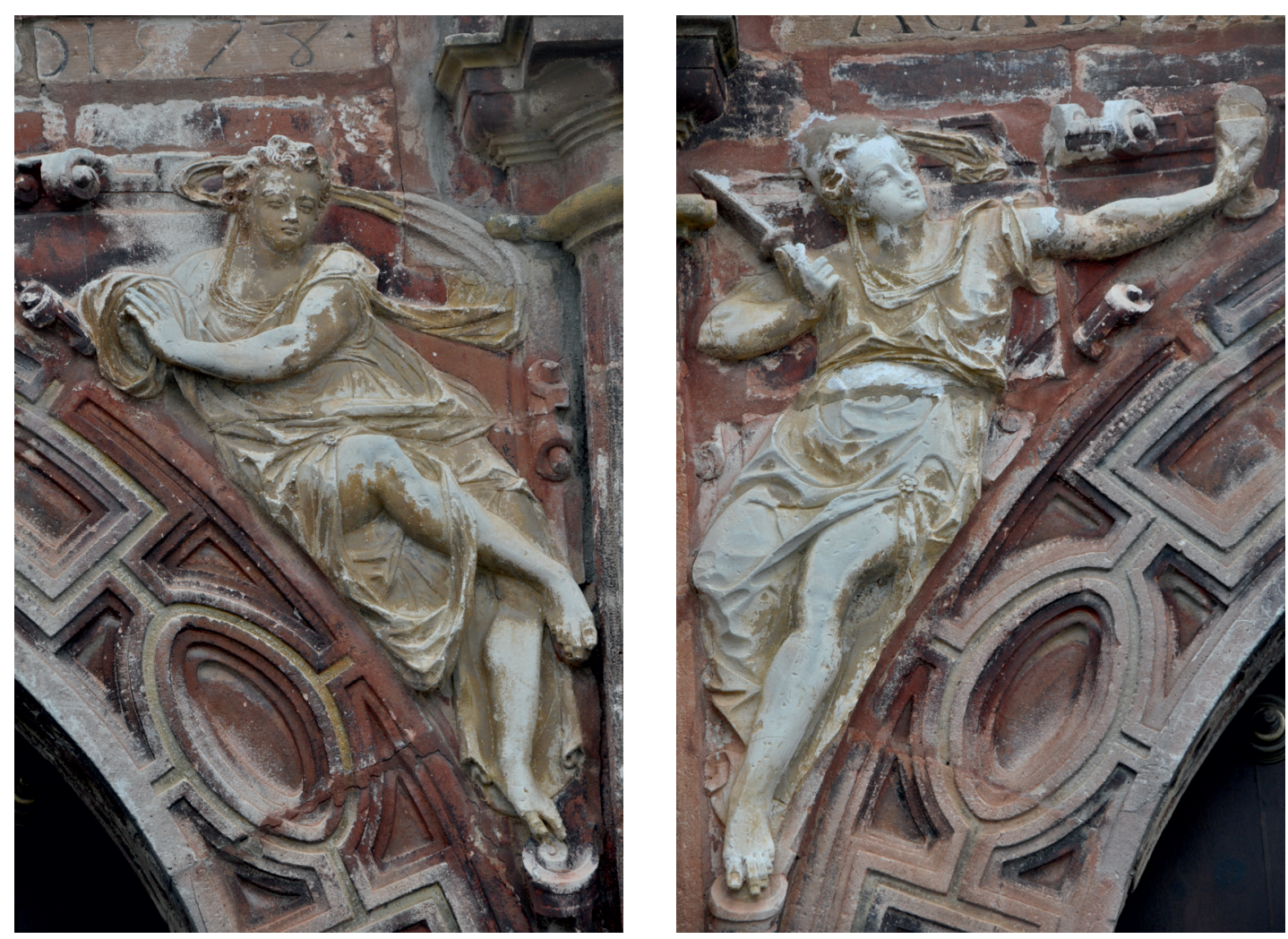

Figs. 4 y 5. Córdoba. Cañete de las Torres. Parroquia de la Asunción. Portada oeste. Detalle de los relieves de las enjutas del primer cuerpo. Fotografías del autor.

lar lo ofrece el diseño del ya citado Alonso Barba para el convento dominico de Jaén en 1582. La portada de Cañete queda articulada por dos semicolumnas dórico-toscanas en el centro, y pilastras del mismo orden en los extremos, organizándose con tres nichos con dos veneras en las calles laterales, y semibóveda de cuarterones con querubines en la central (fig. 6). En la decoración de la rosca de su arco se sigue con mayor fidelidad el citado modelo de Hernán Ruíz II. A partir del friso parece claro que la estructura ha sido reformada, ya que la decoración de las enjutas ha sido mutilada. Originalmente debió contar con pequeñas aletas, similares a las que suelen flanquear las hornacinas de este momento, y que hoy son difíciles de identificar en el caso de Cañete. Un modelo para este cuerpo, podría ser el de la portada de San Miguel Arcángel en Andújar (Jaén), datada en 1530. Otros modelos más cercanos cronológicamente serían los remates de las portadas de Hernán Ruíz II para el Patio del Cabildo de la Catedral de Sevilla ${ }^{33}$. Con independencia de todo ello, parece claro que el autor de la fachada conocía los modelos que aparecían en la tratadística flamenca del momento.

La portada ofrece un problema de montaje notable. La parte alta de las columnas del cuerpo inferior ha tenido que inclinarse hacia los lados, para permitir ubicar los relieves de las enjutas. Esto hace que el friso presente un espacio libre entre el triglifo a eje con la columna y el que se dispone sobre el arranque del arco. Si esto no fuera suficiente problema, los pedestales no están suficientemente embutidos en la pared, sobresaliendo varios centímetros, lo que deja al descubierto un importante sector sin decoración (fig. 2). Parece claro que la modernidad decorativa y

33 Morales, 1996: 43. 
la calidad escultórica contrastan notablemente con los problemas de montaje que parecen ser originales y no fruto del paso del tiempo.

El análisis de esta portada puede utilizarse para entender la posible formación de su autor. A pesar de su origen cordobés, su primera obra apunta a una experiencia previa desarrollada entre la saga de los Hernán Ruiz y los círculos jiennenses. En cualquier caso, si se hubiera examinado en Córdoba, como parece posible, habría sido bajo la influencia de Hernán Ruíz III $^{34}$. Personaje de compleja biografía, parece que estaría en Madrid en 1571, aunque trabajando en los años sucesivos en destinos tan distantes como Écija, Morón, Jerez, Málaga en 1582 o Sevilla en 1586. Todo esto dificultaría una formación personalizada, aunque también le vincularía con diferentes círculos artísticos. Además, su estilo era más sobrio que el planteado por Rojas en Cañete. De lo que no cabe duda es que esta portada de su etapa inicial ofrece unas soluciones decorativas muy diferentes a las de sus obras posteriores, como demuestra su comparación con la portada del Convento de Santo Domingo de Sanlúcar de Barrameda ${ }^{35}$.

Un dato conflictivo en la biografía de Rojas parte de una relación de méritos del ingeniero. Según este documento, el arquitecto elaboraría un informe sobre las defensas de

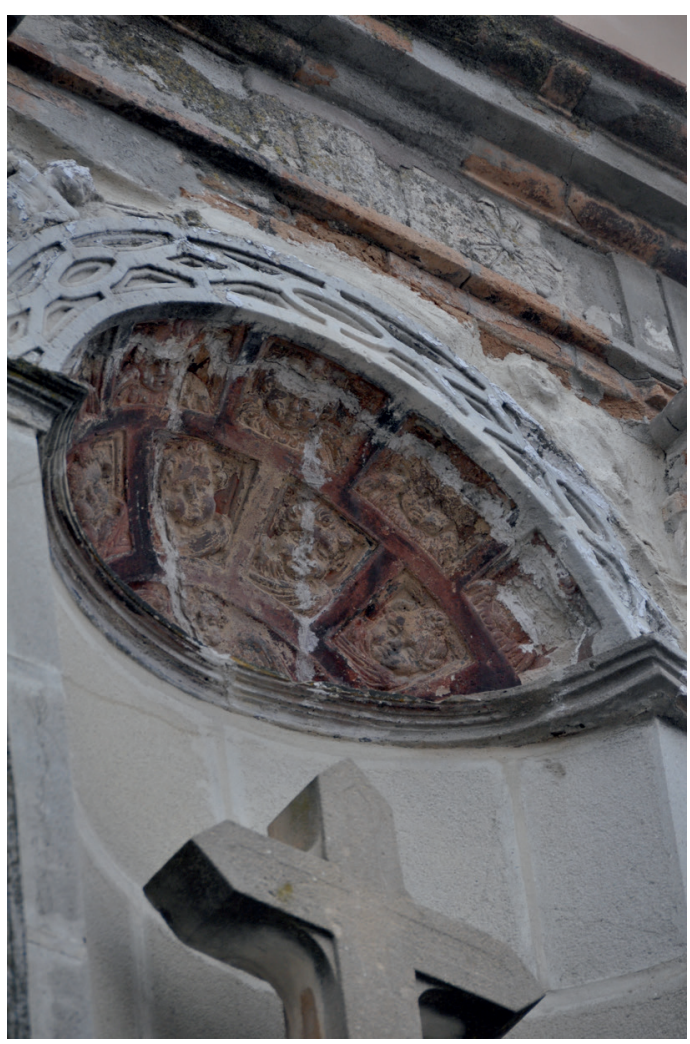

Fig. 6. Córdoba. Cañete de las Torres. Parroquia de la Asunción. Portada oeste. Detalle de hornacina central del segundo cuerpo. Fotografía del autor. Pamplona también en 1578 , año en que está fechada esta portada de Cañete ${ }^{36}$. Este dato ha sido considerado erróneo por diferentes autores, ya que no sería hasta 1588 cuando el maestro informara sobre los cimientos de la ciudadela, trabajo que no se menciona en la relación. Esto permite mantener al maestro cantero en el sur, sin ninguna relación aún con la ingeniería militar.

\section{El Escorial: posibles contribuciones a partir de su experiencia previa}

Los años de Cristóbal de Rojas en El Escorial están aún mal documentados, por lo que hay que moverse aún en el plano de las hipótesis. En 1579 debía estar aún en Sevilla, tras su fallido viaje a Nueva España. Hasta el momento no se ha podido documentar dónde coincidió con Tiburcio Spanocchi en su viaje a la corte a inicios de 1579, quien asegura que lo conoció antes de llegar a Madrid ${ }^{37}$. Una posibilidad es que el ingeniero se trasladara desde Sicilia hasta Cádiz o Málaga, pasando posteriormente por Sevilla, donde tomaría contacto con el cordobés. Es posible que Spanocchi llegara al sur de España siguiendo el camino emprendido por otros como Cesare

34 Camacho, 1986: 81-94.

35 Morales, 1982: 17-20.

${ }^{36}$ Archivo General de Simancas (AGS). Guerra Antigua, Leg. 262, fol. 76. Cfr. Cámara, 2005: 36-37. Ver también Echarri, 2000: 156-157 y Tarifa, 2015: 517-534.

37 Cámara, 2014: 135-161. 
Arbasia, a quien pudo conocer con Pablo de Céspedes antes de 1579, en Roma ${ }^{38}$. Otra opción menos probable es que el maestro cantero decidiera probar fortuna lejos de Sevilla y su entorno, como por el ejemplo en el ámbito granadino o levantino y allí coincidiera con el recién llegado. En cualquier caso, debió pasar poco tiempo entre que Rojas declinara la opción filipina por la obra escurialense.

Parece evidente que en su etapa inicial Rojas no tuvo relación con la ingeniería militar. Sería la selección por parte de Spanocchi, u otros contactos en la corte, lo que le permitiría hacerse cargo de los proyectos defensivos de finales de siglo. Aquí encaja la noticia conocida de que su formación correría junto a la de Juan de Barasoain, antes de 1600, ambos bajo la formación del italiano $^{39}$. Una relectura de los documentos conocidos sobre Spanocchi hace difícil que fuera Barasoain el que formara a Rojas, ya que mientras éste había sido enviado al frente, aquel seguía iniciándose con el italiano a finales del siglo XVI. Así, una cuestión importante es valorar dónde se desarrolló la formación de Rojas en matemáticas. Si se inició en Salamanca, como hiciera Juan Cedillo Díaz, sería bajo la tutela de Bartolomé Barrientos (ca. 1520-Granada, 1580), antes de que se fundara la academia de matemáticas salmantina en 1590, siendo esto improbable. En Toledo aún no se había creado institución docente de este tipo en 1589, lo cual también parece descartarlo. De nuevo, el papel de Spanocchi en esta formación, quizás apoyado por el propio Herrera, pueda servir de solución.

La llegada de Spanocchi fue la base del proyecto de crear una generación de ingenieros matemáticos españoles, de la que el joven Rojas formaría parte. Aquí se encontraría con Juan de Herrera y sus intentos de crear un centro de formación matemática. Cuando Rojas debió llegar a la corte, el arquitecto escurialense se encontraba enfermo y haría testamento el 20 de febrero de $1579^{40}$. A pesar de esto, el arquitecto no dejaría la actividad laboral hasta 1594, tres años antes de su fallecimiento, por lo que no debe descartarse que mantuvieran la estrecha relación que les supone la historiografía decimonónica. El estado de salud del arquitecto, unido a las nuevas obligaciones del proceso constructivo, llevaron a contratar a personajes como Francisco de Mora, Pedro del Yerom, Francisco de Atui, Francisco González Heredero, Yuste González o Roque Solario ${ }^{41}$. Otras fuentes apuntan los nombres de otros canteros trabajando en la obra de estos años, tales como García de Alvarado ${ }^{42}$. Todos estos son reputados técnicos con trayectorias previas en la zona, lo que les llevó a adquirir buenos sueldos en la obra escurialense.

El nombre de Rojas no aparece entre estos registros. Una primera explicación es que no hubiera alcanzado el rango de los anteriores. Otra opción es que su vínculo con el Escorial no fuera con la obra en sí misma, sino con los círculos matemáticos de Herrera. Esto explicaría que Rojas mantuviera posteriormente la relación con el arquitecto en las academias matemáticas, y con Spanocchi como ingeniero militar, mientras que la relación con Minjares parece que no existiera. Minjares sería nombrado maestro mayor de la Casa Lonja de Sevilla en 1585, una obra diseñada por Juan de Herrera. Siendo Rojas conocedor de la realidad andaluza, y concretamente sevillana, que Herrera optara por enviar a su aparejador principal y no a dicho maestro, o al menos no enviarlo junto con él a dirigir las obras de la Lonja, muestra la confianza en uno sobre el otro. Aunque no por iniciativa de Herrera, Rojas sí volvió al sur, de nuevo junto a Spanocchi. Fue entonces cuando creó sociedad con Asensio de Maeda y con Diego de Velasco para la realización de la Puerta de Triana y la portada de la Aduana ${ }^{43}$. Al año siguiente, Rojas es enviado a

38 Sánchez, 2003: 699-710.

39 Cámara, basándose en documentación sobre los méritos de Barasoain, indica que fue este el que formó a Rojas. Cámara, 1992: 97. En cambio, la formación del propio Barasoain se llevó a cabo desde 1594, como demuestra la certificación de Spanocchi publicada en Sobradiel, 2006: 225-226. Esto hace improbable que Barasoain formara a Rojas, en lo que debe ser una mala lectura de lo que debió ser una formación conjunta de los dos ingenieros bajo la tutela del italiano.

40 Fernández, 2004: 55

41 Fernández, 2004: 57.

42 González/Aramburu-Zabala/Alonso/Polo, 1991: 33.

43 Morales, 2000: 245-252. 
Cádiz y a Gibraltar, junto con Spanocchi. Las continuas ausencias de Minjares obligaron a buscar un maestro interino, cargo que recayó en manos de Alonso de Vandelvira. Rojas debía tener buena opinión de él, ya que cuando dejó el cargo en 1607 afirmó que era tan competente que aunque hubiera estado en Roma habría que haberlo traído de alli ${ }^{44}$. Parece claro que no aspiraba a dirigir las obras de la Lonja.

Hasta este momento, Cristóbal de Rojas se había dedicado a proponer proyectos, ahondar en su formación matemática, y a ponerla en práctica como ingeniero en Bretaña ${ }^{45}$. Sorprendería por tanto que su principal apoyo para convertirse en ingeniero militar, el informe del capitán general de artillería, Juan de Acuña Vela, lo describiera como alguien de "muy buena información de él, por haber hecho algunas obras grandes de arquitectura, que han salido muy buenas y que se le entiende obra de cantería y que sabe muy bien la matemática". Todo ello resulta cuando menos exagerado pues por el momento, su obra de cantería más notable es la de Cañete, además de lo que pudiera hacer en el Escorial, si finalmente tuvo alguna participación en la obra del monasterio.

\section{El ingeniero en Cádiz y sus sucesivos matrimonios}

Los diferentes estudios sobre Rojas han clarificado los años centrales de su biografía, y no le han prestado atención a su etapa final. Al respecto parece importante tratar de sus matrimonios. Hasta ahora sólo se le conocía como esposa a María (o Marina) Basozábal, también conocida como María Spínola ${ }^{46}$, quien fue madre del también ingeniero Bartolomé de Rojas Basozábal (1606- $)^{47}$. Sin embargo, como se ha dicho, existía un matrimonio previo con María Rodríguez, pero también uno posterior. El 26 de junio de 1610 se casa con Francisca de Estrada Ávalos, hija de Andrés de Estrada y de Gusteria (probablemente Eusteria) de Ávalos ${ }^{48}$. Había nacido en Úbeda, siendo testigo el gobernador de Cádiz Manuel de Benavides, como lo había sido Fernando de Ágreda en el matrimonio de 1600. Solo cuatro años debió durar este enlace ya que Rojas moriría tras el asalto a La Mámora (actual El-Mehdiya, Marruecos) en 1614. Según carta fechada el 7 de octubre de 1614, se le dio licencia para volver a la península debido a su edad y enfermedad. En otra misiva del día 12 del mismo mes, ya se le daba por muerto ${ }^{49}$. El Archivo Histórico de Cádiz

44 Cámara, 1998: 111.

45 Takayanagi, 2006: 31-43.

46 “"El capitán Cristóbal / de Rojas y doña / Marina casados / y velados]. En la ciudad de Cádiz ocho días del mes de junio de / mil y seiscientos años yo el bachiller Rodrigo Pérez cura de / la dicha ciudad desposé por palabras de presente / que se hicieron verdadero matrimonio con mandamiento del / señor provisor y dispensa suya en las amonestaciones / que el sacro concilio dispone. Al capitán Cristóbal / de Rojas ingeniero y por él y en su nombre por virtud de su poder al señor don Fernando de Ágreda/ gobernador y capitán a guerra de la dicha ciudad // con doña Marina de Basozábal natural de Ro/ siendo testigo el señor deán don Rodrigo de Villavicencio / y don (i) de Villavicencio y don Manuel de / Benavides y otros muchos en fe de lo cual lo / firmé fecho ut supra. El bachiller Rodrigo Pérez (rúbrica)". Archivo Parroquia de Santa Cruz (Cádiz) (APSCC). Libro de Matrimonios 1, ff. 49v-50 (1600).

47 "[Bartolomé] En Cádiz diez y ocho de marzo de seiscientos y / seis (¿) yo Rodrigo Pérez cura de esta ciudad bau/ticé a Bartolomé hijo del capitán Cristóbal de Rojas, / y de doña Marina de Spíndola fue su padrino / don Lorenzo de Villavicencio advertirle de sus / obligaciones y parentesco principal y firmé. El bachiller Rodrigo Pérez”. Archivo Parroquia de Santa Cruz (Cádiz). Libro de Bautismos 2, f. 39.

48 "[Cristóbal de Rojas / y doña Francisca de Estrada/velados] En Cádiz veintiséis de junio de [mil] seiscientos diez años yo el / Bachiller Calar cura de la dicha ciudad habiendo presidir co/da puesta por el señor con desposé por pala/bras de que hubieron verdadero matrimonio y velamiento / eclesiástico del capitán Cristóbal de Rojas con doña Francisca / de Estrada Ávalos hija de Andrés de Estrada y de doña Gusteria de Ávalos nacida en la ciudad de Úbeda fueron / testigos el gobernador don Manuel de Benavides y don / Juan Francisco Moreno y don Luis de Soto y Jerónimo de / Castro y otras muchas personas y feligreses". APSCC, Libro de Matrimonios 2, f. 66v. (1610)

49 "Lo que ahora hay es, que el capitán Cristóbal de Rojas, ingeniero de Vuestra Majestad, a cuyo cargo estaban estos fuertes del Puntal y Matagorda, ha venido muy enfermo, y a la hora que ha llegado a su casa se murió". Fernando de Añasco. Cádiz, 12 de octubre de 1614. Archivo General de Simancas. Mar y Tierra, 734. Cfr. "El capitán Cristóbal de Rojas, ingeniero militar del siglo XVI'. Memorial de ingenieros y revista cientifico-militar. 24, 1879 , p. 189. 
no conserva ningún testamento asociado a Cristóbal de Rojas en estos años. Tampoco ha aparecido ninguno de cualquiera de sus dos últimas esposas. Este documento habría servido para confirmar muchos de los datos ofrecidos en este trabajo.

Una última cuestión a valorar es la participación de Rojas en la iglesia del Sagrario de Sevi1la. Como ya publicó Falcón ${ }^{50}$, existe documentación que apunta a Zumárraga, Alonso de Vandelvira y Cristóbal de Rojas como autores de las trazas ${ }^{51}$. Según parece, el proyecto se iniciaría con fuerza en enero de 1615, según los cabildos celebrados en enero de este año. En cambio, Rojas había fallecido antes del 12 de octubre del año anterior. Las posibilidades serían: que las trazas estuvieran realizadas desde años atrás, o que la fuente del siglo XVIII no sea muy exacta.

\section{Conclusiones}

Del análisis de los datos anteriores se pueden concluir algunas cuestiones sobre la biografía de Cristóbal de Rojas. En primer lugar, parece muy probable que se trate del maestro cantero nacido en Cañete de las Torres (Córdoba) alrededor de 1552. A través del análisis de sus primeras obras e intervenciones, puede decirse que se formó con la saga de los Hernán Ruíz, conociendo la obra de autores jiennenses y manejando tratados italianos, españoles y flamencos. La portada de la iglesia de la Asunción de su pueblo natal fechada en 1578 puede considerarse hasta el momento su primera obra. Meses después renunciaría a trasladarse a Filipinas como maestro de cantería del nuevo gobernador Gonzalo Ronquillo. En cambio, pasaría a formarse en ingeniería y matemática con Tiburcio Spanocchi en la corte, entrando en contacto con Juan de Herrera y la obra del Escorial. Su labor durante estos años es aún difícil de valorar por la escasez de documentación. Por último, no ha sido posible localizar su testamento, pero sí un último matrimonio con Francisca de Estrada Ávalos en Cádiz en 1610. Con todo esto se insiste en la presencia de maestros canteros andaluces en otras obras de la península, mientras los arquitectos cortesanos intentaron imponer su nueva estética en el sur peninsular a fines del siglo XVI.

\section{APÉNDICE DOCUMENTAL}

\section{Documento 1}

Pagos a Cristóbal de Rojas como autor de la portada de la iglesia parroquial de Cañete la Real (Córdoba). Archivo General Obispado de Córdoba (AGOC). Visita General n. ${ }^{\circ}$ 6.226/01. Leg. 14. Pieza 10. F. $9 \mathrm{r}-9 \mathrm{v}$

[portada] Debe cargársele más ciento y / setenta y siete mil y dos/cientos y cincuenta maravedís que / pagó a Cristóbal de Rojas / cantero por la hechura y manos / y toda costa excepto la piedra / y madera de la portada nueva//que en la dicha iglesia acabó el / año pasado de setenta y ocho / y esto conforme a la tasación / hecha por Hernán Ruiz cantero / mayor de este obispado y fue/ tasada la dicha obra en otros / catorce mil maravedies más y el dicho / Cristóbal de Rojas le hizo suel/ta y gracia a la dicha fábrica / de esto mostró mandamiento del / prelado y cartas de pago del / dicho cantero./

[traída de piedra] descárguensele más veinte / y nueve mil y ochocientos y cua/renta y tres maravedís que costa/ron la traída de la piedra que / se trajo de Santiago para / la dicha portada según consta por / el dicho su libro y conocimientos y / exámenes.

\footnotetext{
50 Falcón, 1977: 41-42.
}

${ }^{51}$ El texto del fondo del Conde del Águila es del siglo XVIII y dice exactamente: "que los cimientos se dieron por buenos y de toda primera según los habían / reconocido con las zarpas y resalto de ellos; y que tienen a más de lo que decían como facultativos se hacían cargo que / tres maestros insignes como fueron Vandelvira, maes/tro del rey don Felipe II el capitán Cristóbal de / Rojas ingeniero del mismo rey y el maestro mayor/ Zumárraga artífices tan grandes como lo pública/ban sus obras". AHPS. Fondo Conde del Águila. F. 537. Rollo 54. 
[maestro mayor] descárguensele más seis ducados que / pago al dicho maestro mayor / por la ocupación de ir / a tasar la dicha portada. Mos/tró mandamiento del señor provisor/ y carta de pago/

[elevación] y descárguensele más siete / mil y trescientos y cuaren/ta y cuatro maravedís que se ta/ só (¿) para en cuenta de la ele/vación que está haciendo/ para las puertas de la dicha / iglesia de Inés de Nápoles vecina/ de Jaén. Mostró carta de / pago y mandamiento del señor provisor.

f. 10r. [peones] Y descárguensele más no/venta y dos maravedís que pagó/ a dos peones por cerrar el / arco de la puerta mayor.

\section{BIBLIOGRAFÍA}

Arrighetti, Chiara; Piero Carusone; Michele Ceccaroni y Daniele Zavalloni (2009). "Gli Antonelli, una grande familia di ingegneri militari romagnoli del Cinquecento al servicio dei re di Spagna”. Studi Romagnoli, LX, pp. 565-583.

Barea López, Oscar (2015): Heráldica y genealogía en el sureste de Córdoba (ss. XIII-XIX). Linajes de Baena, Cabra, Carcabuey, Doña Mencía, Iznájar, Luque, Monturque, Priego, Rute, Valenzuela y Zuheros. Tomo II. ¿Madrid?: Bubok Publishing.

Bustamante García, Agustín (1994): La octava maravilla del mundo (Estudio histórico sobre El Escorial de Felipe II). Madrid: Editorial Alpuerto.

Camacho Martínez, Rosario (1986). “Aportaciones al estudio de Hernán Ruíz III”. En: Apotheca, 6, pp. 81-94.

Cámara Muñoz, Alicia (1992): “Juan de Herrera y la Arquitectura militar”. En: Aramburu-Zabala Higuera, Miguel Ángel; Gómez Martínez, Javier (eds.). Juan de Herrera y su influencia. Camargo: Universidad de Cantabria.

Cámara Muñoz, Alicia (1998): Fortificación y ciudad en los reinos de Felipe II. Madrid: Nerea.

Cámara Muñoz, Alicia (2005): "La ciudadela de Pamplona bajo los Austrias". En: AA.VV: Ciudades Amuralladas. Pamplona: Gobierno de Navarra, pp. 36-37.

Cámara Muñoz, Alicia (2014): "Cristóbal de Rojas. De la cantería a la ingeniería”. En: Cámara, Alicia y Revuelta, Bernardo (coords.). Ingenieros del Renacimiento. Madrid: Fundación Juanelo Turriano, pp. 135-161.

Cruz Fernando, Isidoro (2001): Alonso de Vandelvira (1544-ca. 1626/7): tratadista y arquitecto andaluz. Sevilla: Universidad de Sevilla.

Díaz-Trechuelo Spínola, M. ${ }^{a}$ Lourdes (1959): Arquitectura española en Filipinas. 1565-1800. Sevilla: EEHA.

Echarri Iribarren, Víctor (2000): Las murallas y la ciudadela de Pamplona. Pamplona: Gobierno de Navarra.

Emmer, Edwar C. (1999): General History of the Caribbean. New Societies. The Caribbean in the long sixteenth century. Londres: UNESCO.

Espejo Muriel, Carlos (2002): "El espacio religioso en el sur peninsular”. En: Iberia. Revista de la Antigüedad. 5, pp. 110-111.

Falcón Márquez, Teodoro (1977): El Sagrario de la Catedral de Sevilla. Sevilla: Diputación de Sevilla.

Fernández Alba, Antonio (2004): El Escorial: metáfora en piedra. Madrid: CSIC.

Florido Trujillo, Gema (1996): Hábitat rural y gran explotación en la depresión del Guadalquivir. Sevilla: Junta de Andalucía.

González, María del Carmen; Aramburu-Zabala, M. Ángel; Alonso Ruíz, Begoña y Polo Sánchez, Julio J. (eds.) (1991): "Artistas cántabros de la Edad Moderna: su aportación al arte hispánico". Santander: Institución Mazarrasa-Universidad de Cantabria.

Herrera García, Francisco Javier (2014): "La etapa sevillana de Alonso de Vandelvira (1588-1609). Nuevas contribuciones". En: Laboratorio de Arte. 26, pp. 95-119.

Luengo, Pedro (2018): The Convents of Manila: Globalized Architecture during the Iberian Union. Quezon City: Ateneo University Press.

Marías, Fernando (1985): La arquitectura del Renacimiento en Toledo (1541-1631). Madrid: CSIC.

Mariátegui, Eduardo de (1880): El Capitán Cristóbal de Rojas, ingeniero militar del siglo XVI: apuntes históricos por el coronel Eduardo de Mariátegui. Madrid: Memorial de Ingenieros.

Marzo, Ildefonso (1851): Historia de Málaga y su provincia. Tomo II. Málaga: Francisco Gil de Montes.

Morales, Alfredo J. (1982): "La portada del convento de Santo Domingo en Sanlúcar de Barrameda, obra de Cristóbal de Rojas". Revista de Arte Sevillano, 1, pp. 17-20.

Morales, Alfredo J. (1984): La Sacristía mayor de la Catedral de Sevilla. Sevilla: Diputación de Sevilla.

Morales, Alfredo J. (1996): Hernán Ruiz “el Joven”. Madrid: Akal.

Morales, Alfredo J. (2000): "La etapa sevillana de Juan de Minjares". Felipe II y las artes. Madrid: Universidad Complutense, pp. 245-252.

Recio Mir, Álvaro (1999): “Sacrum Senatum”: las estancias capitulares de la Catedral de Sevilla. Sevilla: Universidad de Sevilla-Fundación Focus-Abengoa.

Ríos, Esperanza de los (2001): "Los informes de Cristóbal de Rojas y Julio César Fontana para hacer un muelle y un puente sobre el río Guadalete en Jerez de la Frontera". En: Laboratorio de Arte. 14, pp. 13-25.

Rodríguez Estévez, Juan Clemente (1996): "Los canteros de la obra gótica de la Catedral de Sevilla (1433-1528)". En: Laboratorio de Arte, 9, pp. 49-71. 
Rojas, Cristóbal (1598): Teórica y práctica de la fortificación. Madrid: Luis Sánchez.

Rojas Clemente y Rubio, Simón de (2001): Viaje a Andalucía: "Historia natural del Reino de Granada (1804-1809)". Barcelona: Griselda Bonet Girabet.

Sánchez López, Juan Antonio (2003): "Cesare Arbassia, un pintor italiano para los círculos humanistas hispanos del siglo XVI”. En: Villar García, M. B. y Pezzi Cristóbal, P. (eds.): Los extranjeros en la España Moderna. Actas del I Coloquio internacional. Málaga: Universidad de Málaga, Tomo II, pp. 699-710.

Sobradiel, Pedro I. (2006): La Aljafería filipina. 1591-1597. Los años de hierro. Zaragoza: Instituto de Estudios Islámicos y del Oriente Próximo.

Sobradiel, Pedro I. (2015): Tiburcio Spanoqui. Ingeniero mayor y arquitecto militar e hidráulico del rey. Aportaciones sobre su trayectoria profesional. Zaragoza: Institución Fernando el Católico.

Takayanagi, Shinichi (2009): "On Activities of Cristóbal de Rojas in Cádiz after the assault of 1596". Journal of Architecture and Planning, 74, pp. 273-281.

Takayanagi, Shinichi (2006): “Actividades de Cristóbal de Rojas en la expedición de Bretaña (Francia). Fortificación durante el período de la intervención militar de Felipe II en la guerra civil de Francia: construcción del Fuerte de Blavet y del León". Castillos de España, 144, pp. 31-43.

Tarifa, María Josefa (2015): "Ingenieros y maestros de obras del recinto fortificado de Pamplona en el siglo XVI". En AA.VV. Fortified Heritage: Management and Sustainable Development. Pamplona: Ayuntamiento de Pamplona, pp. 517-534.

Torre Vasconi, José R. de la (1952): El Guadamecil. Córdoba: Ayuntamiento de Córdoba.

Vandelvira, Alonso de (Geneviéve Barbé-Coquelin de Lisle) (1977): El Tratado de arquitectura de Alonso de Vandelvira. Albacete: Caja de Ahorros Provincial de Albacete.

Vignola, Jacome de (1593): Regla de las cinco órdenes de Arquitectura.(trad. Patricio Caxesi) Madrid, Antonio Mancelli.

Vredeman de Vries, Jean (1565): Das Ander Buech. Amberes: Cock.

Vredeman de Vries, Jean (1577): Architectura. Amberes: Chez Gerard Smits.

Vredeman de Vries, Jean (1577): Architectura. Amberes: Gerhardt de Jode.

Fecha de recepción: 15-II-2017

Fecha de aceptación: 14-VI-2017 